\title{
An Inventory Control Model for Deteriorating Items Under Demand Dependent Production with Time and Stock Dependent Demand
}

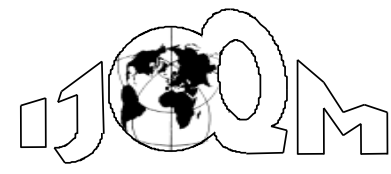

DOI: $10.46970 / 2021.27 .4 .2$

Volume 27, Number 4

December 2021, pp. 321-336
Sanjay Sharma

Anand Tyagi

BB Verma

Ajay Kumar Garg Engineering College

(sanjaysharma698@gmail.com)

(dranandtyagi@gmail.com)

(vermabb@akgec.ac.in)

Sachin Kumar

KIET Group of Institutions

(sachin.kumar@kiet.edu)

In inventory control models where most of the studies are focused on demand, it is obvious that the profit can only be improved by handling the demand of the items according to the fluctuations and pattern of the market ups and downs. In most of the models, demand is taken as time-dependent, pricedependent, and stock-dependent for one complete cycle of the model, which is not realistic in the case of low- life products with a high rate of deterioration like milk products, vegetables. It is also not possible to fix the demand for such items for the entire cycle of the model. In the current study, we have assumed different demands at the different stage of the model which can help to improve the profit as well as to control the deterioration. We have assumed timedependent demand from the initial to the end of the stock level, after that we have assumed demand as price dependent which is the key of the current study and a better approach for handling low-life items. For low-life items, production is also a very important key parameter as it can directly affect the profit. Therefore, in the current study, we have assumed production of items as demand dependent and deterioration is taken time-dependent, a shortage is allowed under partial backlogging. The model is validated by taking numerical data along with a real example based on the model.

Keywords: Price and Stock Dependent Demand, Deterioration, Partial Backlogging

\section{Introduction}

In business organizations, the most important issue is to maintain the availability of the items according to their demand in the market as most of the items undergo decay or deteriorate over time. The item with low life is critical to monitor and handle during their stock like liquids such as gasoline, alcohol. Many research papers were published based on the deterioration of low life items, but in most of the studies, their deterioration assumed constant which is not a realistic aspect. In the case of low life items, even in some research studies, the demand is also assumed to be a constant which is not a good option especially for the entire period of the cycle. 
Satisfaction of customers during stock out period is also a big issue to handle, in general when the demand of the customers is not satisfied then they can take two decisions, either they can wait for the items or they can move for other options to meet their demands. So, it is obvious that it is not possible to fulfil the orders at the earliest time even if we start the production with maximum capacity. Deterioration is the most important aspect of any inventory especially for the items with very low life. In the current model, we have assumed deterioration as time-dependent, as we have considered those inventory items whose self-life is very low.

We have also taken the demand of the items as price dependent because the production of such items is always dependent upon the price, as they are not seasonal items so the concept of taking price-dependent demand is more realistic.

In the market, there are always a group of customers with a mental makeup to wait for their product after shortage or out of stock period but there are some customers who are not ready to wait as, they need their item at the earliest time gap. The first model in inventory based on the above said issues was discussed by Ghare and Schrader for the first time where the demand was taken as exponential function of time. In addition to this; Abad implemented a new approach to customer's impatience and developed an inventory model. An integrated lot size inventorybased production model for deteriorating items developed by [1]. Where [2] made an attempt in the direction of time- lags, and presented an inventory control technique to discuss production-based optimization model with continuously distributed timelags.

In the inventory control model deterioration also affect the cost and as a result the total average profit also gets affected, various models were developed by considering deterioration, a model on spoilage was presented by [3], in which production-based policies of the deteriorating items for the product of declining market was presented. Also, in the same direction [4] investigated production-based model for the decaying items where the demand was assumed as exponentially decreasing. For multi-lot-size items, [5] discussed and implemented a new approach in the history of inventory models by presenting an integrated model for deteriorating items. In most of the earlier studies before [6] the demand of the items was assumed as constant but [6] presented a production-based inventory model where the demand was assumed as variable and the model was focused on deteriorated items. The concept of inflation in demand was presented by [7], where a control model was developed but, in this paper, demand was assumed constant again, [7] implemented some changes and presented a multi-echelon profit maximization supply chain model in which the effect of inflation on demand is considered and variable rate of demand was taken. A new approach of reserve money-based model was implemented by [8] and the model was developed under constant demand and partial backlogging where supplier credits option in an inflationary environment was also assumed. Products like milk items, vegetables are having high deterioration as their self-life is very low. For such product an attempt was made by [9] wherein the developed model demand was taken as a function of time and shortages were permitted which is a more realistic assumption for low life items. For the same low-life items, a different assumption of taking trended demand was assumed by [10] and they formulated a model for deteriorated items under shortages. 
By considering the concept of ramp type demand in which a different pattern of demand for different stages of the cycle was taken by [11], where in this model an economic production quantity for deteriorated items was developed. When the items are out of stock then we have to start production again and we have to satisfy the backorders first. In the same way [12] developed a logistics model for deteriorated items in which the main focus was on optimal returned policy and backorders. Inflation play important role in inventory management as its effects can be monitored on inventory so in the same way [13] discussed the inventory model under storage capacity and developed an inventory model where time-dependent demand and inflation were assumed. In addition to partial backlogging and multivariate consumption rate [14] developed an inventory model for decaying items. Price adjustment means we have to adjust payment according to the requirement of the buyer, [15] implemented the effect of price adjustment where the demand of the model was assumed as price-dependent.

The market price is always affecting the inventory also; the demand of the items affected by the price of an item, for such deteriorated items [16] presented a profit maximization-based model where the demand was taken price dependent. In this model, the production was assumed demand dependent, and the shortage was permitted. The storage of items in the stock is again a very critical stage of the model where we have to maintain the items in the proper storage conditions, in the same way [17] discussed an inventory model for decaying items under stock-dependent demand in which multi-item in the stock were assumed.

An inventory model under the concept of fuzzy environment, price-dependent demand, and deterioration were presented by [18]. [19] developed and investigated an EPQ model for deteriorating items with price-sensitive demand and shortages.

Some items are seasonal and their demand is also based as per their need and season, so, by considering this fact in mind, [20]explained and presented an inventory model by allowable shortages and deteriorating items having seasonal and stock-dependent demand. The demand in most of the study was assumed to be single parameter based but [21] assumed the demand a function of price and stock dependent and presented an optimal pricing and ordering policy for deterioration under partial backlogging. Inventory preservation also plays important role in the management of inventory models, by assuming revenue sharing on preservation an inventory model under price-sensitive and stock-dependent demand was developed by [22].

By assuming the effect of inflation on inventory items and different rates of deterioration in a different stage of the model [23] developed a production-based inventory model for deteriorating items under stock and price dependent demand where shortages were permitted and inflation in the price of the item was also considered to take more profit, some delay in payments also accepted. Instead of time or stock dependent demand, [24] studied reliability dependent demand and presented an inventory model for deteriorating items with partial backlogging where [25] took the holding cost as a function of time and studied EPQ inventory model for deteriorating items considering stock dependent demand. In supply chain management, the role of the inflationary environment is very important, [26] implemented the concept of the inflationary environment on deteriorated items and presented a supply chain model with linear stock-dependent demand. 
[27] Developed an inventory control model in which a two-echelon inventory model with stock-dependent demand and variable holding cost for deteriorating items was considered. Based on two levels of trade credits, [28] presented an integrated inventory model with variable holding cost under two levels of tradecredit policy.

Trade credits were also found very suitable and affected during inventory controlling of the items, in the same way [29] used the concept of trade credits and developed a two-echelon supply chain model by taking advertisement and stock dependent demand for imperfect production systems under deterioration. [30] Updated the model of [29] by introducing the concept of cash flow and taking multiple suppliers' trade credit in the model. By implementing the effect of inflation on deteriorated items and use of preservation technology of [30], [31] discussed an inventory model in which the demand was assumed as time and price dependent and model were presented under a shortage.

By considering multi-item inventory for deteriorating products [32] developed a two-echelon inventory model with price-and stock-dependent demand where the effect of trade credits was also considered.

\begin{tabular}{|l|c|c|c|c|c|c|c|}
\hline \multicolumn{1}{|c|}{ Authors } & $\begin{array}{c}\text { Stock } \\
\text { Dependent } \\
\text { Demand }\end{array}$ & $\begin{array}{c}\text { Selling } \\
\text { Price } \\
\text { Dependent } \\
\text { Demand }\end{array}$ & $\begin{array}{c}\text { Time- } \\
\text { Dependent } \\
\text { Demand }\end{array}$ & $\begin{array}{c}\text { Time- } \\
\text { Dependent } \\
\text { Deterioration }\end{array}$ & $\begin{array}{c}\text { Production } \\
\text { based on } \\
\text { Demand }\end{array}$ & $\begin{array}{c}\text { Partial } \\
\text { Backlogging }\end{array}$ & $\begin{array}{c}\text { Variable } \\
\text { Holding } \\
\text { Cost }\end{array}$ \\
\hline $\begin{array}{l}\text { Kumar and } \\
\text { Sharma } \\
(2000)\end{array}$ & NO & NO & YES & NO & NO & YES & YES \\
\hline $\begin{array}{l}\text { Pervin et al. } \\
(2017)\end{array}$ & YES & NO & YES & NO & NO & NO & YES \\
\hline $\begin{array}{l}\text { Pervin et al. } \\
(2018)\end{array}$ & YES & NO & NO & NO & NO & YES \\
\hline $\begin{array}{l}\text { Saha, and } \\
\text { Chakrabarti } \\
(2018)\end{array}$ & YES & NO & NO & YES & NO & NO & YES \\
\hline $\begin{array}{l}\text { Tripathi et } \\
\text { al. (2019) }\end{array}$ & YES & NO & YES & YES & NO & NO & YES \\
\hline $\begin{array}{l}\text { Saha and } \\
\text { Sen (2019). }\end{array}$ & NO & YES & NO & YES & NO & NO & YES \\
\hline $\begin{array}{l}\text { Pervin et al. } \\
(2019)\end{array}$ & YES & YES & NO & YES & NO & NO & YES \\
\hline $\begin{array}{l}\text { Das et al. } \\
(2020)\end{array}$ & NO & YES & NO & NO & NO & YES & NO \\
\hline $\begin{array}{l}\text { Pervin et al. } \\
(2020)\end{array}$ & YES & YES & NO & NO & NO & YES & NO \\
\hline $\begin{array}{l}\text { Xie et al. } \\
(2021)\end{array}$ & NO & NO & YES & YES & NO & YES & NO \\
\hline $\begin{array}{l}\text { Halim et al } \\
(2021)\end{array}$ & YES & YES & NO & NO & NO & YES & NO \\
\hline $\begin{array}{l}\text { Present } \\
\text { Paper }\end{array}$ & NO & YES & YES & YES & YES & YES & NO \\
\hline
\end{tabular}


An inventory model in which the demand was considered price dependent developed by [33]where the application of preservation technology in inventory control system under partial backlogging was carried out. A generalized inventory model for deteriorated items in which selling-price dependent demand undertimedependent deterioration was developed by [34]

By introducing a new approach on demand [35] presented an integrated vendorbuyer model with quadratic demand under inspection policy and preservation technology, where [36] developed a two-warehouse probabilistic model with price discount on backorders under two levels of trade-credit policy. In the above models, the demand was considered either price dependent or selling price dependent but [37] introduced a deteriorating inventory model with preservation technology underprice-and stock-sensitive demand. The effect of deterioration in the model [37] was not considered but [38] took the effect of deterioration and presented a joint inspection and inventory control model for deteriorating items with time-dependent demand and deteriorating rate.

In the inventory control models very less study was taken in the area of overtime production but it affects the profit of the production, also the price of the item was considered linear but [39] developed an overtime production inventory model for deteriorating items with nonlinear price and stock dependent demand. By introducing the concept of back-ordered in inventory model [40] presented an EOQ model with inflation in a cloudy-fuzzy environment

In most of the inventory models, it is commonly seen that the demand is taken constant, time-dependent, stock dependent, price dependent, and selling price dependent commonly for the entire cycle but this phenomenon is not up to the mark for the items whose life is very low and the rate of deterioration is very high. Even the rate of deterioration was not taken time-dependent in the past studies hence; there is a research gap for the items with low life and high rate of deterioration.

In the current study, after analyzing all the work done in the area of controlling the inventory for the items of low life, we have used a new approach of taking two parameters-based demand and developed the model which must be helpful for the manufacturers so that they can handle the inventory in a better way.

We have developed this model under different demand parameters in a different stage of the model which is more realistic as it is sometimes not possible to assume the same demand throughout the cycle.

Also, in this model, we have taken production as demand dependent which makes this study more useful to maximize the profit. Deterioration is also accepted in the model and assumed as time-dependent which is more effective for low-life products. The shortage is also accepted in the model and assumed as partially backlogged and during the stock out, period there is no deterioration as there are no items in the stock even when production starts, we have assumed that we have to satisfy the demand of the customers those are waiting for the items based on first come first serve.

\section{Assumptions}

We make these assumptions. The production rate is directly proportional to demand. Deterioration is permitted and assumed as time-dependent. Demand is assumed timedependent for a subsequent time and price-dependent for the rest period of interval. 
Shortages permitted under partially backlogged. The production rate is assumed higher than the demand rate. The planning horizon is infinite.

\subsection{Notation}

\begin{tabular}{|c|c|c|}
\hline $\mathrm{I}(\mathrm{t})$ & $=$ & Level of inventory at any instant of time. \\
\hline $\mathrm{R}$ & $=$ & Present rate of production in the inventory. \\
\hline$\alpha$ & $=$ & Constant $(\alpha>1)$ \\
\hline $\mathrm{D}(\mathrm{p})$ & $=$ & Demand of the items $=\left\{\begin{array}{ll}\mu \mathrm{t} & \text { if } 0<t<T \\
\frac{\gamma}{\mathrm{p}^{\delta}} & \text { if } \quad \mathrm{T}<t<T+\lambda\end{array}\right\}$ \\
\hline $\mathrm{p}$ & $=$ & Selling price of the item during the inventory cycle. \\
\hline $\mathrm{T}$ & $=$ & Time when the items are available in the stock. \\
\hline$\psi$ & $=$ & Time duration in which inventory becomes zero. \\
\hline $\mathrm{T}+\lambda$ & $=$ & Time during zero inventory after meeting all backlogged. \\
\hline$\beta$ & $=$ & The time slot till which production is going on. \\
\hline I & $=$ & Waiting time of customer. \\
\hline $\mathrm{K}, \gamma, \delta$ & $=$ & Constants. \\
\hline $\mathrm{S}$ & $=$ & Cost of placing of an order. \\
\hline $\mathrm{Z}(\tau)$ & $=$ & Rate of backlogging during the stock-out period. \\
\hline$K_{0}, K_{1}=$ & & Constants where $K_{0}<1, K_{1} \geq 0$ \\
\hline $\mathrm{P}_{\mathrm{c}}$ & $=$ & Unit cost of production. \\
\hline h & $=$ & Per unit cost of holding the inventory \\
\hline Q & $=$ & Amount of total production. \\
\hline T.P. & $=$ & Total profit \\
\hline T. A. P. & $=$ & Total average profit \\
\hline
\end{tabular}

\section{Mathematical Formulation of the Model}

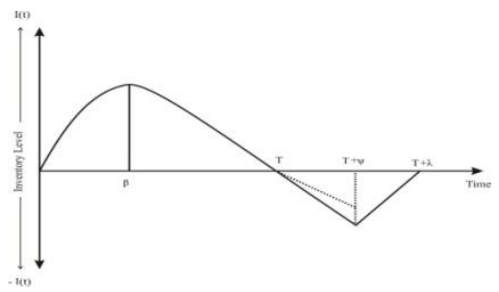

Figure 1 Production Inventory System for the Vendor

According to the graphical representation of the model the production stat at $t=0$ and production is going on till $\mathrm{t}=\beta$. Now at $\mathrm{t}=\beta$ the production stopped and as a result of continuous demand and active deterioration on the items in the inventory the stock of inventory is going decay and at the stage $\mathrm{t}=\mathrm{T}$ the inventory level becomes zero and shortage occurs.

Now as we are in the stock out period and $t=T+\psi$ is assumed the time when we have moved to a maximum level of shortage, at this time we have to start the production again to satisfy the backorders also we have to satisfy the demand of the items as per the waiting time. The model is expressed by the following differential equations 


$$
\begin{array}{lc}
\frac{\mathrm{dI}(\mathrm{t})}{\mathrm{dt}}=\mathrm{R}-\mathrm{ktI}(\mathrm{t})-\mathrm{D}(\mathrm{p}) & 0 \leq \mathrm{t} \leq \beta \\
\frac{\mathrm{dI}(\mathrm{t})}{\mathrm{dt}}=-\mathrm{ktI}(\mathrm{t})-\mathrm{D}(\mathrm{p}) & \beta \leq \mathrm{t} \leq \mathrm{T} \\
\frac{\mathrm{dI}(\mathrm{t})}{\mathrm{dt}}=-\mathrm{D}(\mathrm{p}) \mathrm{B}(\tau) & \mathrm{T} \leq \mathrm{t} \leq \mathrm{T}+\psi \\
\frac{\mathrm{dI}(\mathrm{t})}{\mathrm{dt}}=\mathrm{R}-\mathrm{D}(\mathrm{p}) \mathrm{Z}(\tau) & \mathrm{T}+\psi \leq \mathrm{t} \leq \mathrm{T}+\lambda
\end{array}
$$

Following are the boundary conditions: $\mathrm{I}(0)=0, \mathrm{I}(\mathrm{T})=0, \mathrm{I}(\mathrm{T}+\lambda)=0$

By using above boundary conditions, the solutions of the Eqn. (1), (2) and (3) are given by

$$
\begin{aligned}
& I(t)=\left[\alpha D t-\mu \frac{t^{2}}{2}+\frac{k}{6} \alpha D t^{3}-k \mu \frac{t^{4}}{8}\right] e^{-k \frac{t^{2}}{2}} \\
& I(t)=-\left[\mu \frac{t^{2}}{2}+k \mu \frac{t^{4}}{8}\right] e^{-k \frac{t^{2}}{2}} \\
& I(t)=-(k+\mu)\left[\left(\frac{T^{2}-t^{2}}{2}\right)+k\left(\frac{T^{4}-t^{4}}{8}\right)\right] e^{-k \frac{t^{2}}{2}}
\end{aligned}
$$

It is obvious that customers are very much impatient so this is not possible that a person who has high level need of the item will wait for the product hence in the period of stock out $\mathrm{t} \in[\mathrm{T}, \mathrm{T}+\psi]$ only a minimum amount of demand $Z(\tau)$ only backlogged, where $Z(\tau)$ is assumed as a decreasing function of $\tau$. There for we can assume

$Z(\tau)=K_{0} e^{-k_{1} \tau}$

Where, $\mathrm{K}_{0}, \mathrm{~K}_{1}$ are some contents of backlogged assumed during shortages.

Also, we have assumed that the customers willing for the product are entertained according to first come first serve basis. So, we can assume that between the time of interval $\mathrm{t} \in[\mathrm{T}, \mathrm{T}+\lambda]$, now $\tau$ would depend upon the backorders as it is obvious that all previous backorders can only be fulfilled first before filling the new backorder.

Again, it is obvious from the Figure-1 that in the time interval $(\mathrm{T}, \mathrm{T}+\psi)$ we are actually not having any production so when there is a demand of the item, customer only need to wait for the product. Therefore, between the time period $t \in[\mathrm{T}, \mathrm{T}+$ $\psi]$ the waiting of the customer is given by

$I=T+\psi-t-I \frac{(t)}{R}$

Here we can see that when we are satisfying the demands of the customers between $[\mathrm{T}+\psi, \mathrm{T}+\lambda]$ the current status of backlog is decreasing with a rate of $\mathrm{R}$, on the other hand we are taking some new orders now, therefore in the time interval $t \in$ $[\mathrm{T}+\psi, \mathrm{T}+\lambda]$ the waiting time for the new costumers is given by $\tau=-\mathrm{I}(\mathrm{t}) / \mathrm{R}$. 
Then we have

$\frac{\mathrm{dI}}{\mathrm{dt}}=-\frac{\gamma}{\mathrm{p}^{\delta}} \mathrm{Z}(\mathrm{T}+\psi-\mathrm{t}-\mathrm{I}(\mathrm{t}) / \mathrm{R}), \mathrm{T} \leq \mathrm{t} \leq \mathrm{t}+\psi 1$

Whose solution is

$\mathrm{I}(\mathrm{t})=\frac{\mathrm{R}}{\mathrm{K}_{1}}\left(\log \left[\frac{\mathrm{R}}{\mathrm{DK}_{0} \mathrm{e}^{\mathrm{K}_{1}(\mathrm{t}-\mathrm{T}-\psi)}+\mathrm{R}-\mathrm{DK}_{0} \mathrm{e}^{-\mathrm{K}_{1} \psi}}\right]\right)$

Similarly, for $t \in[\mathrm{T}+\psi, \mathrm{T}+\lambda]$,

$\left.\frac{d I}{d t}=\mathrm{R}-\mathrm{DZ}\left(\frac{-\mathrm{I}(\mathrm{t})}{\mathrm{R}}\right),(\mathrm{T}+\psi) \leq \mathrm{t} \leq \mathrm{T}+\lambda\right)$

$\frac{\mathrm{dI}}{\mathrm{dt}}=\mathrm{R}-\mathrm{DK}_{0} \mathrm{e}^{-\mathrm{K}_{1}\left(\frac{-\mathrm{I}(\mathrm{t})}{\mathrm{R}}\right)}$

From Eq. (11)

$$
\begin{aligned}
& \mathrm{I}(\mathrm{T}+\psi)=\frac{\mathrm{R}}{\mathrm{K}_{1}}\left(\log \left[\frac{\mathrm{R}}{\mathrm{DK}_{0}+\mathrm{R}-\mathrm{DK}_{0} \mathrm{e}^{-\mathrm{K}_{1} \psi}}\right]\right) \\
& \mathrm{I}(\mathrm{t})=\frac{\mathrm{R}}{\mathrm{K}_{1}}\left(\log \left[\frac{\mathrm{R}}{\mathrm{Re}^{-\mathrm{K}_{1}(\mathrm{t}-\mathrm{T}-\psi)}-\mathrm{DK}_{0} \mathrm{e}^{-\mathrm{K}_{1}(\mathrm{t}-\mathrm{T})}+\mathrm{DK}_{0}}\right]\right), \mathrm{T}+\psi \leq \mathrm{t} \leq \mathrm{T}+\lambda
\end{aligned}
$$

We know that $I(\mathrm{~T}+\lambda)=0$, put this value in Eq. (14)

$$
\begin{aligned}
& I(T+\lambda)=\frac{R}{K_{1}}\left(\log \left[\frac{R}{R e^{-K_{1}(\lambda-\psi)}-D K_{0} e^{-K_{1} \lambda}+D K_{0}}\right]\right) \\
& R=R e^{-K_{1} \lambda} e^{K_{1} \psi}-D K_{0} e^{-K_{1} \lambda}+D K_{0} \\
& \psi=\frac{1}{K_{1}} \log \left[\frac{e^{K_{1} \lambda}\left(R-D K_{0}\right)+D K_{0}}{R}\right]
\end{aligned}
$$

The production in the model is occurs in two different slots i.e., between $[0, \beta]$ and $[\mathrm{T}+\psi, \mathrm{T}+\lambda]$. Therefore, the total production in the interval is given by

$\mathrm{Q}=\mathrm{R} \cdot \beta+\mathrm{R} \cdot(\mathrm{T}+\lambda-\mathrm{T}-\psi) \mathrm{Q}=\mathrm{R} \cdot \beta+\mathrm{R} \cdot(\lambda-\psi)$

\section{Calculation Inventory Costs}

4.1 Cost of holding the inventory: The cost of holding the inventory is the cost for holding the inventory in the stock from initial to the end of the cycle.

Hence,

\section{Cost of Holding}

$$
\begin{aligned}
& =h \int_{0}^{\beta} I(t) \cdot d t+h \int_{\beta}^{T} I(t) \cdot d t \\
& \quad=h \int_{0}^{\beta}\left[\alpha D \mathrm{t}-\mu \frac{\mathrm{t}^{2}}{2}+\frac{\mathrm{k}}{6} \alpha \mathrm{Dt} \mathrm{t}^{3}-\mathrm{k} \mu \frac{\mathrm{t}^{4}}{8}\right] \mathrm{e}^{-\mathrm{k} \frac{\mathrm{t}^{2}}{2}} d t-h \int_{\beta}^{T}\left[\mu \frac{\mathrm{t}^{2}}{2}+\mathrm{k} \mu \frac{\mathrm{t}^{4}}{8}\right] \mathrm{e}^{-\mathrm{k} \frac{\mathrm{t}^{2}}{2}} d t
\end{aligned}
$$


Since $\mathrm{K}$ is very small, so omitting the higher powers of $\mathrm{K}$

$$
\begin{aligned}
& \quad=h\left[\frac{(10 \alpha D+\mathrm{k} \mu)}{20} \beta^{2}-\frac{\mu}{6} \beta^{3}+\frac{k D}{24} \beta^{4}(1-3 k)-\frac{k \mu}{20} \beta^{5}\right]-h\left[\frac{\mu}{6}\left(T^{3}-\beta^{3}\right)\right. \\
& -k \frac{\mu}{40}\left(T^{5}-\beta^{5}\right) \\
& =h\left[\frac{(10 \alpha D+\mathrm{k} \mu)}{20} \beta^{2}-\frac{\mu}{6} \beta^{3}+\frac{k D}{24} \beta^{4}(1-3 k)-\frac{k \mu}{20} \beta^{5}\right]-h\left[\frac{\mu}{6}\left(T^{3}-\beta^{3}\right)-\right. \\
& \left.k \frac{\mu}{40}\left(T^{5}-\beta^{5}\right)\right]
\end{aligned}
$$

4.1.1 Production Cost: The cost of production of the inventory is the cost exist during production of the items

$=\mathrm{P}_{\mathrm{c}}(R \beta+R(\lambda-\psi))$, where $\mathrm{P}_{\mathrm{c}}$ is the unit cost of production

\subsubsection{Set up Cost}

$=\mathrm{S}$

4.1.3 Sales Revenue: The sales of revenue is the total profit received from sales; therefore, the sales revenue is given by

$p \cdot D T+p \cdot R(\lambda-\psi)$

4.1.4 Deterioration Cost: The cost due to deterioration of the items is the product of number of deteriorated units and unit cost of deterioration. = Initial Inventory- Total Demand

$=0-\mathrm{P}_{\mathrm{c}} \int_{0}^{t_{1}} D(p) d t=\mathrm{P}_{\mathrm{c}} \int_{0}^{t_{1}} \mu t d t=\mathrm{P}_{\mathrm{c}}\left[\mu \frac{t^{2} 1}{2}\right]$

Now we have to calculate the total profit in the model between the time gap $[0, \mathrm{~T}+\lambda]$

Total Profit $($ T.P) $=$ Total revenue - Total costs

$=$ Sales revenue - \{production cost + set up cost + inventory holding cost + deterioration cost)

Total Profit (T.P)

$=\left[p \cdot(D T+R(\lambda-\psi))-\mathrm{P}_{\mathrm{c}}\{R \beta+R(\lambda-\psi)\}-\xi-h\left[\frac{(10 \alpha D+\mathrm{k} \mu)}{20} \beta^{2}-\frac{\mu}{6} \beta^{3}+\right.\right.$

$\left.\left.\frac{k D}{24} \beta^{4}(1-3 k)-\frac{k \mu}{20} \beta^{5}\right]-h\left[\frac{\mu}{6}\left(T^{3}-\beta^{3}\right)-k \frac{\mu}{40}\left(T^{5}-\beta^{5}\right)\right]-\mathrm{P}_{\mathrm{c}}\left(\mu \frac{t^{2}{ }_{1}}{2}\right)\right]$

Total Average Profit

(T.A.P. $)=\frac{1}{T+\lambda}$. T.P 
Now, we have the following LPP which is faced by the vender Max. T.A.P

$p \geq \mathrm{P}_{\mathrm{c}} \quad$ S.T.T $\geq 0, \lambda \geq 0$,

\section{Case - I: The Product under Non-Perishable}

For the items under non- perishable, we have to take $K=0$, now from Eqn. (5), (6) and (7)

$$
\begin{array}{lr}
I(t)=\left[\alpha \mathrm{Dt}-\mu \frac{\mathrm{t}^{2}}{2}\right] & 0 \leq \mathrm{t} \leq \beta \\
I(t)=-\left[\mu \frac{\mathrm{t}^{2}}{2}\right] & \beta \leq \mathrm{t} \leq \mathrm{T}
\end{array}
$$

After putting $K=0$ equation (18) reduces to

H. $C=h\left[\frac{(\alpha D)}{2} \beta^{2}-\frac{\mu}{6} \beta^{3}+\right]-h\left[\frac{\mu}{6}\left(T^{3}-\beta^{3}\right)\right]$

Now the total profit on the inventory for non - perishable items is

$$
\begin{gathered}
\text { T. } P_{(K=0)}=\left[p \cdot \left(D T+R(\lambda-\psi)-P_{c}\{R \beta+R(\lambda-\psi)\}-S\right.\right. \\
\left.-h\left[\frac{(\alpha \mathrm{D})}{2} \beta^{2}-\frac{\mu}{6} \beta^{3}+\right]-h\left[\frac{\mu}{6}\left(T^{3}-\beta^{3}\right)\right]-(\alpha D \beta-D T) v\right] \\
\text { T. A. } P_{(K=0)}=\frac{1}{T+\lambda}\left[p \left(D T+R(\lambda-\psi)-P_{c}\{R \beta+R(\lambda-\psi)\}\right.\right. \\
-\left[p \cdot \left(D T+R(\lambda-\psi)-P_{c}\{R \beta+R(\lambda-\psi)\}-S\right.\right. \\
\left.\left.-h\left[\frac{(\alpha D)}{2} \beta^{2}-\frac{\mu}{6} \beta^{3}+\right]-h\left[\frac{\mu}{6}\left(T^{3}-\beta^{3}\right)\right]-(\alpha D \beta-D T) P_{c}\right]-(\alpha D \beta-D T) P_{c}\right]
\end{gathered}
$$

\section{Numerical Example}

A gasoline distributor has a weekly demand that is approximately, the average demand is $1,500,000 p^{-3}$, gallons per week; however. His supply is replenished every 2 weeks. He must pay 500 per gallon. His cost of capital is $0.8 \%$ per week. He recovers this cost in the price he charges for gasoline, but if any remains in inventory when the next order arrives, he charges a holding cost based on this interest rate and the value of the inventory. If the present rate of production in the inventory $1830000 p^{-3}$ units/week and Rs. 16 is the selling price, unit cost ofdeterioration is 9per unit, and demand constant is Rs. 1,300,000 distributor runs out of supply during the period.The borrowed gas must be returned when his supply is replenished. What is the optimal total average profit? Here, given values are as follows:

$$
\delta=+2 \quad D=1,500,000 p^{-3}, \quad R=1830000 p^{-3} \frac{\text { units }}{\text { week }}
$$




$$
\begin{array}{lll}
\mathrm{P}_{\mathrm{c}}=9 & K=.002 & h=. \frac{0001}{\text { unit }} \\
K_{0}=0.8 & K_{1}=0.6 & p=16
\end{array}
$$

$\gamma=1,300,000 \quad \lambda=1.7 \mathrm{~S}=500$ Output: $\mathrm{T}=1.065$

\section{Sensitivity Analysis}

Table1 Effect on $K$ for Different Variation in $T$

\begin{tabular}{|c|c|c|c|}
\hline S. No. & $\mathbf{K}$ & $\mathbf{T}$ & $\boldsymbol{\beta}$ \\
\hline 1 & .0005 & 1.1224 & 0.6150 \\
\hline 2 & .0006 & 1.1284 & 0.6620 \\
\hline 3 & .0009 & 1.0340 & 0.1652 \\
\hline 4 & .0010 & 1.0480 & 0.6220 \\
\hline 5 & .0012 & 1.0320 & 0.0161 \\
\hline 6 & .0015 & 1.0360 & 0.1732 \\
\hline 7 & .0016 & 1.0020 & 0.0015 \\
\hline
\end{tabular}

Table 2 Variation in $h$

\begin{tabular}{|c|c|c|}
\hline $\mathbf{H}$ & $\mathbf{T}$ & $\boldsymbol{\beta}$ \\
\hline .00010 & 1.05200 & 0.6314 \\
\hline .00015 & 1.04312 & 0.6218 \\
\hline .00020 & 1.04300 & 0.6217 \\
\hline .00025 & 1.04500 & 0.6228 \\
\hline .00030 & 1.04510 & 0.6235 \\
\hline .00035 & 1.04490 & 0.6264 \\
\hline .00040 & 1.04425 & 0.6111 \\
\hline
\end{tabular}

Example-1

The solution was found to be

$$
\mathrm{p}=12.721 \quad \mathrm{~T}=1.089 \quad \lambda=1.674 \quad \beta=0.578 \quad \psi=0.955
$$

Production cost $=12694.523$, Deterioration cost $=(\alpha \mathrm{D} \beta-\mathrm{DT}) \mathrm{P}_{\mathrm{c}}=767.03$. The lot size $Q$ is $R . \beta+R(\lambda-\psi)=2160$ units

\section{Conclusions}

Current study is based on [16] where demand was assumed price dependent throughout the cycle but in the current model, we have assumed the demand as time and price dependent which is more effective as compared with another parameter. In the present study, we have proved that the total profit is increased by taking different demand parameters for different stages of the model. From Table 1 and Table 2 it 
can be observed that the profit can be increased to backlog demand at the instance of time.

From Table 1 it can be seen that for increased values of $\mathrm{K}$, the total profit is also increased.

- From Table 2 it can be seen that for increased values of $\mathrm{H}$, the total profit is also increased and for decreased values of demand parameter the total profit is also increased.

- Also, it is found that for non-perishable items the demand is the measure part to be monitored carefully especially in the stock out situation.

- It is also observed that we can control the variation in the cost of the item by backlogging the demand during the deterioration period.

- It is also suggested by the outcome of the model that for the perishable product it will be more economical to the vendor that they must backlog the demand so that we can handle the cost which is paid to avoid high cost due to deterioration.

- Also, in this study where we have taken multivariable demand but instead of that, we have also assumed a time-based rate of deterioration which makes the study more realistic in comparison with the previous study at the end the model is being discussed and compared for the non-perishable products.

In the current study we have categories the demand in two variant and we have proved that the total profit can be maximized, even the effect of the main parameters on the profit is also evaluated.

The practical implications of the study can be found as the model directly used for the items those life is low and decaying time is also very high.

\section{Future Scope of the Study}

In the present study, we have used the notation and graphical presentation from [16] which was based on the single price-based demand but in the current model, we have used the concept of multivariable demand which make it more realistic even present study can be more modified by applying some changes in the parameters like we can use two-variable Weibull distribution on deterioration instead of time-dependent. Trade credits and some price discounts on the in-hand inventory may also be assumed.

\section{Acknowledgment}

The authors are grateful to anonymous reviewers for their encouragement and constructive remarks.

\section{References}

1. Caniato, F., Caridi, M., Crippa, L., and Moretto, A.. (2012), "Environmental sustainability in fashion supply chains: exploratory case-based research. International", Journal of Production Economics, Vol. 135, pp. 659-670.

2. Misra, R. B. (1975), "Optimum production lot size model for a system with deteriorating inventory", International Journal of Production Research, Vol.13 (No.1), pp. 495-505. 
3. Choi, S., and Hwang, H. (1986), "Optimization of production planning problem with continuously distributed time-lags', International Journal of Systems Science, Vol.17 (No.10), pp. 1499-1508.

4. Aggarwal, V., and Bahari-Hashani, H. (1991), "Synchronized production policies for deteriorate items in a declining market", IIE Transactions on Operations Engineering, Vol. 23 (No.2), pp. 185-197.

5. Kumar, N., and Sharma, A.K. (2000), "On deterministic production inventory model for deteriorating items with an exponential declining demand", Acta Ciencia Indica, Vol. 26 (No.4), pp. 305-310.

6. Yang, P., and Wee, H. (2003), "An integrated multi-lot-size production inventory model for deteriorating item", Computer and Operations Research, Vol. 30 (No. 5), pp. 671-682.

7. Goyal, S.K., and Giri, B.C. (2003), "The production-inventory problem of a product with time varying demand, production and deterioration rates", European journal of Operational Research, Vol.147 (No.3), pp. 549-557.

8. Singh, S.R., and Diksha. (2009), "Supply chain model in a multi-echelon system with inflation induced demand", International Transaction in Applied Science, Vol.1 (No.1), pp. 73-86.

9. Singh, S.R., and Jain, R. (2009), "Understanding supplier credits in an inflationary environment when reserve money is available", Int. J. of Operational Research, Vol.6(No. 4), pp. 459 - 474.

10. Manna, S.K., and Chiang, C. (2010), "Economic production quantity models for deteriorating items with ramp type demand" ,Int. J. of Operational Research, Vol. 7 (No. 4), pp. 429-444.

11. Manna, S.K., Lee, C.C., and Chiang, C. (2009, "EOQ model for noninstantaneous deteriorating items with time-varying demand and partial backlogging”, International Journal of Industrial and Systems Engineering, Vol. 4(No. 3), pp. 241-254.

12. Sana, S., Goyal, S.K., and Chaudhuri, K.S. (2004), "A production-inventory model for a deteriorating item with trended demand and shortages", European Journal of Operation Research, Vol.157 (No. 2), pp. 357-371.

13. Singh, S. R., and Saxena, N. (2012), "An optimal returned policy for a reverse logistics inventory model with backorder", Advances in Decision Sciences, United Kingdom: Hindawi Publishing Corporation.

14. Kumar, N., Singh, S.R., and Kumari, R. (2012), "An inventory model with timedependent demand and limited storage facility under inflation", Advances in Operations Research, United Kingdom: Hindawi Publishing Corporation.

15. Sharma, S., and Singh, S.R. (2013), “An inventory model for decaying items, considering multivariate Consumption Rate with Partial Backlogging”, Indian Journal of Science and Technology, Vol. 6 (No. 7), pp. 4870-4880.

16. Forghani, K., Mirzazadeh, A., and Rafiee, M. (2013), "A price-dependent demand model in the single period inventory system with price adjustment", Journal of Industrial Engineering, United Kingdom: Hindawi Publishing Corporation. 
17. Sharma, S., Singh, S.R., and Ram, M. (2015), “An EPQ Model for deteriorating items with price sensitive demand and shortages in which production is demand dependent", International Journal of Mathematics in Operational Research, Vol. 23 (No. 2), pp. 245-255.

18. Ghosh, S.K., Sarkar, T., and Chaudhuri, K. (2015), “A multi-item inventory model for deteriorating items in limited storage space with stock-dependent demand", American Journal of Mathematical and Management Sciences, Vol. 34 (No. 2), pp. 147-161.

19. Roy, A. (2015), "Fuzzy inventory model for deteriorating items with price dependent demand", International Journal of Management Science and Engineering Management, Vol. 10 (No. 4), pp. 237-241.

20. Chowdhury, R.R., Ghosh, S.K., and Chaudhuri, K.S. (2015), “An inventory model for deteriorating items with stock and price sensitive demand", International Journal of Applied and Computational Mathematics, Vol. 1(No. 2), pp. 187-201.

21. Singh, S.R., Rastogi, M., and Tayal, S. (2016), "An inventory model for deteriorating items having seasonal and stock-dependent demand with allowable shortages", Proceedings of fifth international conference on soft computing for problem solving. Singapore, pp. 501-513.

22. Khurana, D., Chaudhary, R. (2016),“Optimal pricing and ordering policy for deteriorating items with price and stock dependent demand and partial backlogging", Uncertain Supply Chain Management, Vol. 4 (No. 4), pp. 307318.

23. Mishra, V.K. (2016), "Inventory model for deteriorating items with revenue sharing on preservation technology investment under price sensitive stock dependent demand", International Journal of Mathematical Modelling \& Computations, Vol. 6 (No. 1), pp. 37-48.

24. Patel, S.S. (2017), "Production inventory model for deteriorating items with different deterioration rates under stock and price dependent demand and shortages under inflation and permissible delay in payments", Global Journal of Pure and Applied Mathematics, Vol. 13(No. 7), pp. 3687-3701.

25. Mahapatra, G.S., Adak, S., Mandal, T.K., and Pal, S. (2017), "Inventory model for deteriorating items with time and reliability dependent demand and partial backorder”, International Journal of Operational Research, Vol. 29 (No. 3), pp. 344-359.

26. Pandey, A. (2017), “A study of EPQ inventory model for deteriorating items considering stock dependent demand and time varying holding cost", Journal of Computer and Mathematical Sciences, Vol. 8 (No.7), pp. 323-331.

27. Yadav, A.S., and Swami, A. (2018), "Integrated supply chain model for deteriorating items with linear stock dependent demand under imprecise and inflationary environment", International Journal of Procurement Management, Vol. 11(No. 6), pp. 684-704.

28. Pervin, M. K., Roy, S., and Wilhelm W. G. (2017), "A Two-echelon inventory model with stock-dependent demand and variable holding cost for deteriorating items", Numerical Algebra, Control and Optimization, Vol. 7(No. 1), pp. 21-50. 
29. Pervin, M., Roy, S. K., and Weber, G. W. (2018), "An integrated inventory model with variable holding cost under two levels of trade-credit policy", Numerical Algebra, Control \& Optimization, Vol. 8 (No. 2), pp. 169182.

30. Saha, S., and Chakrabarti, T. (2018), "Two-echelon supply chain model for deteriorating items in an imperfect production system with advertisement and stock dependent demand under trade credit", International Journal of Supply and Operations Management, Vol. 5 (No. 3), pp. 207-217.

31. Tripathi, R.P., Singh, D., and Aneja, S. (2019), “Inventory control model using discounted cash flow approach under multiple suppliers' trade credit and stock dependent demand for deteriorating items", International Journal of Inventory Research, Vol. 5(No. 3), pp. 210-223.

32. Saha, S., and Sen, N. (2019), “An inventory model for deteriorating items with time and price dependent demand and shortages under the effect of inflation", International Journal of Mathematics in Operational Research, Vol. 14 (No. 3), pp. 377-388.

33. Pervin, M., Roy, S. K., and Weber, G. W. (2019), "multi-item deteriorating twoechelon inventory model with price-and stock-dependent demand, A trade-credit policy”, Journal of Industrial \& Management Optimization, Vol. 15 (No. 3), pp. 1345

34. Das, S.C., Zidan, A.M., Manna, A. K., Shaikh, A. A., and Bhunia, A. K. (2020), "An application of preservation technology in inventory control system with price dependent demand and partial backlogging", Alexandria Engineering Journal, Vol. 59 (No. 3), pp. 1359-1369.

35. Rahman, M.S., Duary, A., Shaikh, A.A., and Bhunia, A.K. (2020),“An application of parametric approach for interval differential equation in inventory model for deteriorating items with selling-price-dependent demand", Neural Computing \& Applications, Vol. 32 (No. 17)

36. Pervin, M., Roy, S. K., and Weber, G. W. (2020), “An integrated vendor-buyer model with quadratic demand under inspection policy and preservation technology", Hacettepe Journal of Mathematics and Statistics, Vol. 49 (No. 3), pp.1168-1189.

37. Roy, S. K., Pervin, M., and Weber, G. W. (2020),“A two-warehouse probabilistic model with price discount on backorders under two levels of tradecredit policy", Journal of Industrial \& Management Optimization, Vol. 16(2), 553.

38. Pervin, M., Roy, S. K., and Weber, G. W. (2020), "Deteriorating inventory with preservation technology under-price-and stock-sensitive demand",. Journal of Industrial \& Management Optimization, Vol. 16 (No. 4), 1585.

39. Xie, Y., Tai, A.H., Ching, W. K., Kuo, Y.H., and Song, N. (2021), “Joint inspection and inventory control for deteriorating items with time-dependent demand and deteriorating rate", Annals of Operations Research, Vol. 300 (No.1), pp. 225-265.

40. Halim, M.A., Paul, A., Mahmoud, M., Alshahrani, B., Alazzawi, A.Y., and Ismail, G.M. (2021), “An overtime production inventory model for deteriorating items with nonlinear price and stock dependent demand", Alexandria Engineering Journal, Vol. 60 (No. 3), pp. 2779-2786. 
41. Barman, H., Pervin, M., Roy, S. K., and Weber, G. W. (2021), "Back-ordered inventory model with inflation in a cloudy-fuzzy environment", Journal of Industrial \& Management Optimization, Vol. 17(No. 4), 1913.

\section{About Our Authors}

Sanjay Sharma is Assistant Professor of Mathematics at Ajay Kumar Garg Engineering College, Ghaziabad, UP (Affiliated to AKTU Lucknow) India. His research areas are related to the Inventory Control, Inventory Management, Supply Chain Management and Optimization. He has done his PhD in 2015. He has written many research papers in the area of Inventory Control Management, attended many conferences and he is working as a member of editorial board in various International and National journals.

Anand Tyagi is Assistant Professor of Mathematics at Ajay Kumar Garg Engineering College, Ghaziabad, UP (Affiliated to AKTU Lucknow) India. His research areas are related to the Reliability Theory, Inventory Control and Graph Theory He has done his $\mathrm{PhD}$ in 2007. He has published many research papers in the area of Reliability Theory, Inventory Control. He attended many International and National conferences and he is working as a member of IMA.

B B Verma is working as a Professor of Mathematics at Ajay Kumar Garg Engineering College, Ghaziabad, UP (Affiliated to AKTU Lucknow) India. His research areas are related to the Inventory Control, Inventory Management, Supply Chain Management and Optimization. He has done his $\mathrm{PhD}$ in 2007. He has written some research papers in the area of Inventory Control Management, attended some conferences and heading mathematics department.

Sachin Kumar is working as Associate Professor of Mathematics at KIET Group of Institutions, Delhi -NCR, Ghaziabad, UP, India. His area of research interest is Reliability, Inventory control and optimization. He has done $\mathrm{PhD}$ in Mathematics in the year of 2008. He has published many research papers in referred journals of international repute. He has participated in many international conferences and presents his papers. He has contributed as Co- convenor and organising secretary in organisation of international conferences at his institution. He is active member of editorial board in various international and national journals. He has life membership of ISCA, ISTE, New Delhi and IAENG society of operations research. 